\title{
The bacterial communities of Tuber aestivum: preliminary investigations in Molise region, Southern Italy
}

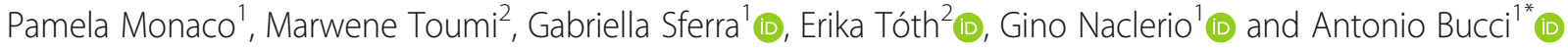

\begin{abstract}
Purpose: Truffles are colonized by a complex microbial community of bacteria, yeasts, and filamentous fungi, whose role has not yet been fully understood. The main purpose of the research was to characterize the bacterial communities associated with Tuber aestivum Vittad. fruiting bodies collected from natural truffle grounds in the Molise region (Southern Italy). Despite it is one of the Italian richest areas of truffles, little is known about truffles in Molise.

Methods: Six ripe fruiting bodies of Tuber aestivum Vittad. and six soil samples were collected in July 2018 at Villa San Michele in the municipality of Vastogirardi, Molise region. Then, soil and truffle microbial communities were analyzed through 165 rRNA gene sequencing on the Illumina MiSeq platform and bioinformatics analyses.

Results: Consistently with previous studies, the main phyla retrieved in the investigated ascocarps were Proteobacteria and Actinobacteria, with the genus Bradyrhizobium particularly represented. Nevertheless, significant differences between soil and truffle microbiota and an unexpected heterogeneity across truffles were observed. It is likely that a specific recruitment of bacteria from soil to ascocarps occurs during the truffle formation and that local-scale factors play an important role in determining the structure of the investigated truffle microbial communities.

Conclusion: Although further analyses (based on a larger soil and truffle sample size and aimed at defining in more detail microbial diversity, soil physical and chemical properties, microclimatic conditions, and vegetation) are required to better understand which are these factors and how they could influence the composition of truffle bacterial communities, this study represents the starting point for a deepened characterization of this economically important product.
\end{abstract}

Keywords: Italian summer black truffle, Tuber aestivum Vittad., Bacterial communities, Next generation sequencing

\section{Introduction}

Most of terrestrial plant roots are colonized by mycorrhizal fungi which play a key role in soils by improving plant water and mineral nutrient uptake and receiving carbon compounds in return (Mello and Balestrini 2018). Among mycorrhizal symbioses, ectomycorrhizae (ECM) are mutualistic relationships between plants (both angiosperms and gymnosperms, as well as shrubs)

\footnotetext{
* Correspondence: antonio.bucci@unimol.it

${ }^{1}$ Department of Biosciences and Territory, University of Molise, Contrada

Fonte Lappone, 86090 Pesche, IS, Italy

Full list of author information is available at the end of the article
}

and fungi (almost exclusively belonging to Basidiomycetes and Ascomycetes). A well-known example of ectomycorrhizal fungi is given by truffles, a polyphyletic group of hypogeous fungi whose fruiting bodies sequester their spores and develop underground, bringing benefits to the forest ecosystems and to the host plant (Pavić et al. 2013; Mäkelä et al. 2015; Vita et al. 2015; Benucci and Bonito 2016; Mello and Balestrini 2018). Different species of truffles are edible and highly sought after due to their organoleptic properties (Vita et al. 2015; Benucci and Bonito 2016). Among these, truffles belonging to the Tuber genus (including more than 180

(c) The Author(s). 2020 Open Access This article is licensed under a Creative Commons Attribution 4.0 International License, which permits use, sharing, adaptation, distribution and reproduction in any medium or format, as long as you give appropriate credit to the original author(s) and the source, provide a link to the Creative Commons licence, and indicate if changes were made. The images or other third party material in this article are included in the article's Creative Commons licence, unless indicated otherwise in a credit line to the material. If material is not included in the article's Creative Commons licence and your intended use is not permitted by statutory regulation or exceeds the permitted use, you will need to obtain permission directly from the copyright holder. To view a copy of this licence, visit http://creativecommons.org/licenses/by/4.0/.
} 
species) are considered very precious and delicious food (Pacioni et al. 2014; Schmidberger and Schieberle 2017). Tuber magnatum Pico, the Italian white truffle, and Tuber melanosporum Vittad., the Périgord black truffle, represent the most valued species on the food market due to their excellent flavor. Tuber spp. are widely distributed across Europe, North America, South East Asia, and limited parts of Africa and South America (Barbieri et al. 2005; Vita et al. 2015; Benucci and Bonito 2016; Iotti et al. 2016; Ye et al. 2018).

Truffles are colonized by a complex microbial community of bacteria, yeasts, and guest filamentous fungi (Splivallo et al. 2015; Vahdatzadeh et al. 2015). Bacteria can be found in inner and outer parts of truffle with densities ranging from a million to a billion cells per gram of fruiting bodies (dry weight) (Vahdatzadeh et al. 2015). They seem to be selected from the soil microbial communities during the early stage of truffle formation and could play an important role in the development, growth, and nutrition of fruiting bodies (Splivallo et al. 2015). Moreover, they contribute to truffle aroma through the production of volatile organic compounds (VOCs) (Splivallo et al. 2015; Vahdatzadeh et al. 2015; Benucci and Bonito 2016; Ye et al. 2018). A combination of culture-dependent and independent methods has been used to extensively investigate truffle-associated bacteria (Splivallo et al. 2015; Vahdatzadeh et al. 2015; Benucci and Bonito 2016) and showed that different Tuber species may harbor diverse bacterial communities, mainly constituted of Proteobacteria, Bacteroidetes, Firmicutes, and Actinobacteria phyla (Vahdatzadeh et al. 2015). Nevertheless, recent studies highlighted that the genus Bradyrhizobium is particularly abundant in several Tuber species (Benucci and Bonito 2016).

Many of these investigations have been focused on $T$. borchii Vittad. and T. magnatum Pico (Sbrana et al. 2002; Barbieri et al. 2005; Barbieri et al. 2007; Pavić et al. 2013; Splivallo et al. 2015) whereas less is known on bacterial communities of $T$. aestivum Vittad. despite its wider geographic distribution (Büntgen et al. 2017). The main purpose of this research was to characterize the bacterial communities associated with Tuber aestivum fruiting bodies collected from truffle grounds in Molise region (Southern Italy), by using next generation sequencing techniques (NGS). Despite it has received less attention, Molise region represents one of the Italian richest areas of truffles.

\section{Materials and methods}

\section{Study area and samplings}

Six ripe fruiting bodies of Tuber aestivum and six soil samples were collected in July 2018 from natural truffle grounds at Villa San Michele in the municipality of Vastogirardi, Molise region (Southern Italy, Fig. 1a). The study area is located at an altitude of about $900 \mathrm{~m}$ above sea level (a.s.l.) with a vegetation composed by Turkey oak (Quercus cerris).

Tuber aestivum ascocarps were collected at a depth of approximately $10 \mathrm{~cm}$ in six different sites at a distance of some meters from each other. Truffles were dug out with the help of an expert person and a hunter/truffle dog by using a spade (Fig. 1b, c, d). Then, they were individually placed in sterile polypropylene containers. In addition, soil samples were also collected using sterile spoons and sterile polypropylene tubes under the fruiting bodies, at a depth of about $10-15 \mathrm{~cm}$. Truffle and soil samples were then transported in a refrigerated container to the laboratory.

Tuber aestivum ascocarps were gently brushed with a sterile soft brush, rinsed with sterile distilled water and stored at $-20^{\circ} \mathrm{C}$ before proceeding with biomolecular investigations. Species identification and maturation stage assessment were performed on the basis of morphological traits by experienced mycologists (Splivallo et al. 2015; Büntgen et al. 2017).

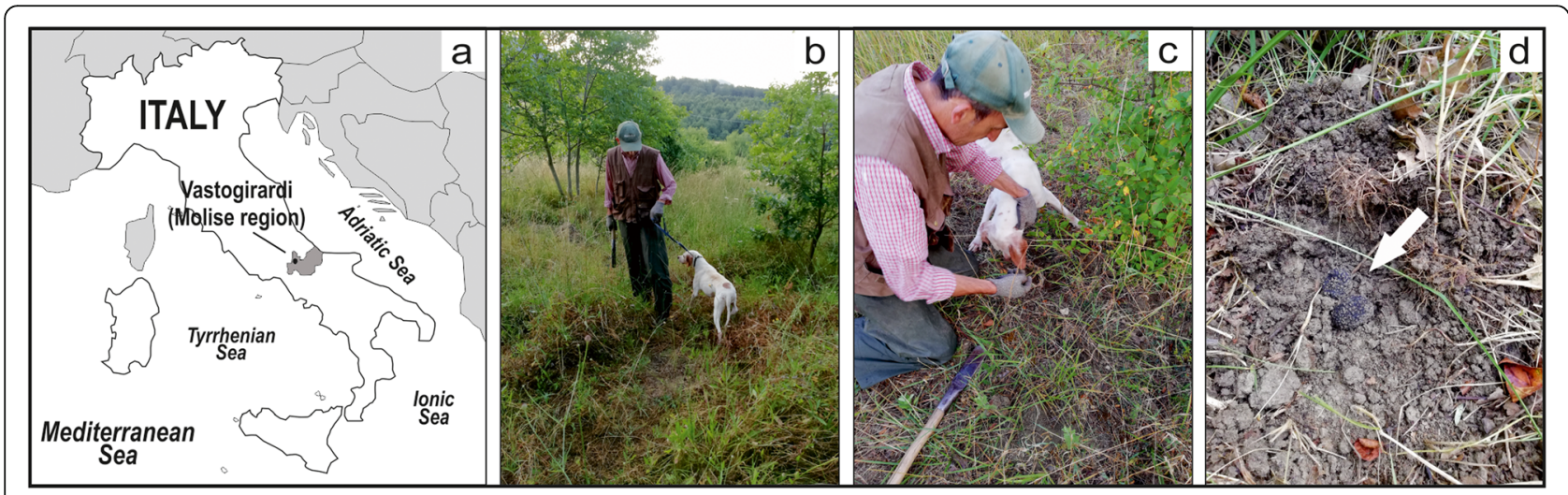

Fig. 1 a Localization of the study area. b, c, d Truffle hunting and ascocarp collection. The white arrow indicates a truffle ascocarp collected during the sampling campaign 


\section{Biomolecular investigations DNA extraction}

DNA was extracted from truffles $(1 \mathrm{t}, 2 \mathrm{t}, 3 \mathrm{t}, 4 \mathrm{t}, 5 \mathrm{t}, 6 \mathrm{t})$ and soil samples $(1 \mathrm{~s}, 2 \mathrm{~s}, 3 \mathrm{~s}, 4 \mathrm{~s}, 5 \mathrm{~s}, 6 \mathrm{~s})$ in order to assess bacterial diversity and taxonomic composition using Illumina amplicon sequencing of $16 \mathrm{~S}$ rRNA genes (sample names with matching numbers indicate truffles and soils collected from the same site within the study area).

Tuber aestivum ascocarps (inclusive of peridium and gleba) were shredded and then pulverized by the addition of liquid nitrogen. Total genomic DNA was subsequently extracted from the fruiting bodies and soils by using the E.Z.N.A. ${ }^{\circledR}$ Plant DNA DS Mini Kit (Ye et al. 2018) and E.Z.N.A. ${ }^{\oplus}$ Soil DNA Kit (Omega Bio-tek, USA) respectively and following the manufacturer's instructions.

\section{S rRNA gene amplicon library preparation and sequencing}

Partial 16S rRNA gene sequences were amplified from extracted DNA using primer pair Probio_Uni $\left(5^{\prime}\right.$-CCTACG GGRSGCAGCAG-3') and Probio_Rev (5'-ATTACC GCGGCTGCT-3'), which target the V3 region of the $16 \mathrm{~S}$ rRNA gene sequence (Milani et al. 2013; Di Luccia et al. 2018). Illumina adapter overhang nucleotide sequences were added to the partial $16 \mathrm{~S}$ rRNA gene-specific amplicons, which were further processed employing the $16 \mathrm{~S}$ Metagenomic Sequencing Library Preparation Protocol (Part \#15044223 Rev. B-Illumina). Amplifications were carried out using a Verity Thermocycler (Applied Biosystems). The integrity of the PCR amplicons was analyzed by electrophoresis on a 2200 TapeStation Instrument (Agilent Technologies, USA). DNA products obtained following PCR-mediated amplification of the 16S rRNA gene sequences were purified by a magnetic purification step involving the Agencourt AMPure XP DNA purification beads (Beckman Coulter Genomics GmbH, Bernried, Germany) in order to remove primer dimers. DNA concentration of the amplified sequence library was determined by a fluorimetric Qubit quantification system (Life Technologies, USA). Amplicons were diluted to a concentration of $4 \mathrm{nM}$, and $5 \mu \mathrm{L}$ quantities of each diluted DNA amplicon sample were mixed to prepare the pooled final library.

$16 \mathrm{~S}$ rRNA gene sequencing was performed using an Illumina MiSeq System (Illumina, San Diego, CA, USA) at the GenProbio srl Laboratory (Milani et al. 2013; Di Luccia et al. 2018).

\section{Bioinformatics analysis}

Following sequencing, the .fastq files were processed using a custom script based on the QIIME software suite (Caporaso et al. 2010). Paired-end read pairs were assembled to reconstruct the complete Probio_Uni/Probio_Rev amplicons.
Quality control retained those sequences with a length between 140 and $400 \mathrm{bp}$ and mean sequence quality score $>20$ while sequences with homopolymers $>7 \mathrm{bp}$ and mismatched primers were omitted.

In order to calculate downstream diversity measures (alpha and beta diversity indices, Unifrac analysis), 16S rRNA Operational Taxonomic Units (OTUs) were defined at 100\% sequence homology using DADA2 (Callahan et al. 2016); OTUs not encompassing at least 2 sequences of the same sample were removed. Notably, this approach allows highly distinctive taxonomic classification at single nucleotide accuracy (Callahan et al. 2016). All reads were classified to the lowest possible taxonomic rank using QIIME2 (Caporaso et al. 2010; Bokulich et al. 2018) and a reference dataset from the SILVA database (Quast et al. 2013).

Biodiversity within a given sample (alpha-diversity) was calculated with Shannon and Chaol indices. Similarities between samples (beta-diversity) were calculated by weighted UniFrac (Lozupone and Knight 2005). The range of similarities is calculated between values 0 and 1. PCoA representations of beta-diversity were performed using QIIME2 (Caporaso et al. 2010; Bokulich et al. 2018).

To identify the core taxa retrieved in the soil and truffle habitats, microbial genera were analyzed for their presence or absence in each sample and the related Venn diagram drawn by Venny 2.1 (Oliveros 20072015).

For differential abundance analysis between soil and truffle microbial communities at phylum level, a negative-binomial-based approach in tandem with paired Wald test, as available in DESeq2 version 1.24.0 (Love et al. 2014) in $R$ environment ( $R$ core team 2019), was performed.

In order to structure soil, truffle, or soil-truffle microbiomes, co-occurrence patterns were determined by applying rcorr function from Hmisc package in $\mathrm{R}$ (Harrell Jr et al. 2019) and calculating correlations among species abundances by Pearson method. Correlation coefficient significance was also assessed by using the same $R$ function.

Networks were composed by selecting highly significant correlations $(P<0.01)$ between species abundances. Specifically, networks were derived from abundances of species identified in the soil or in the truffle habitat and also from a dataset composed by the species identified in the soil and truffle habitats together. The analysis and visualization of the networks and the related statistical analysis were performed by Cytoscape (Shannon et al. 2003) and R.

Network structure was assessed by measuring the node degree of each node that is the number of partners each node has. Node degree is related to sparsity, a 
property that relies on the number of connections observed in the network (Busiello et al. 2017). In a "complete network," each node is connected with all other nodes; thus, the average number of node degree is equal to the number of nodes minus 1 . A lower mean node degree is a sign of a sparser network. The larger is the network the higher is the sparsity (Busiello et al. 2017). The density, as the number of observed edges respect all possible ones, shows how dense are the connections per node. In biological networks, density has been demonstrated to be lower than 0.1 (Leclerc 2008). This observation indicates that the structure of a biological network fits with a general sparse connected graph which gives evolutionary advantages in terms of resilience to possible network damages (Leclerc 2008; Pavlopoulos et al. 2011).

To have a stronger evidence about network structure, the centrality of the microbial populations present in the combined habitat network was measured in order to define the relative importance of soil species with respect to the truffle ones. To achieve this goal, node degree distributions of soil-truffle network were analyzed by considering first the totality of the nodes present, then only the nodes related to species identified in the soil habitat, and finally only the species identified in the truffle habitat. The frequency distribution of node degree provides information about the structure of a network (sparsity), and it is often used to compare the nature of networks (Liu et al. 2011; Nacher and Akutsu 2013; Suweis et al. 2013; Grilli et al. 2017). In order to achieve this goal, Welch's unequal variance $t$ test (Welch 1947) on node degree distributions was applied.

Nodes relevant to the structure of the microbiomes (keystone nodes) were identified according to their node degree and betweenness centrality that is a measure of the shortest paths that pass through the node (Freeman 1977).

To test the robustness of the network and its ability to be resilient to species loss, an approach based on the progressive removal of species (nodes) according to their relevance in the network structure (Iyer et al. 2013; Ruiz et al. 2017), both considering node degree and betweenness centrality, was applied. The area under the curve (AUC) was calculated according to Gini's formula.

\section{Results}

NGS results allowed to obtain detailed information about the composition of microbial communities in soil samples and associated with summer black truffle (Tuber aestivum) ascocarps collected from six different truffle grounds in the Molise region (Fig. 1).

The analyses highlighted a high percentage $(\approx 75 \%)$ of shared taxa at genus level (511). On the other hand, 114 $(\approx 17 \%)$ and $55(\approx 8 \%)$ genera were unique in soil and truffle, respectively (Venn diagram in Additional file 1).
Actually, even though it seems that truffle could host peculiar bacterial communities including taxa absent in soil, those genera retrieved only in the truffle group were not found in all the analyzed six ascocarps and were often present at very low relative abundances.

Overall, important differences were found between soil and truffle groups even though a significant heterogeneity of ascocarp microbiota has also been detected. Principal Coordinate Analysis (PCoA) based on weighted UniFrac index revealed that the truffle microbial communities varied from those of the soil (Fig. 2). The rarefaction curves obtained by using Shannon and Chao1 indices for each sample highlighted a greater microbial diversity in soil samples compared to the Tuber aestivum fruiting bodies and differences among samples of the truffle group in terms of $\alpha$-diversity (Additional file 2).

Differential abundance analysis at phylum level revealed the presence of 14 categories with significantly different relative abundances between soil and truffle (Fig. 3). Among these, the phyla Tectomicrobia, Nitrospirae, Fibrobacteres, Planctomycetes, Gemmatimonadetes, Chloroflexi, and Acidobacteria were more abundant in soil whereas Proteobacteria, Saccharibacteria, Firmicutes, Cyanobacteria, Fusobacteria, Tenericutes, and other unclassified

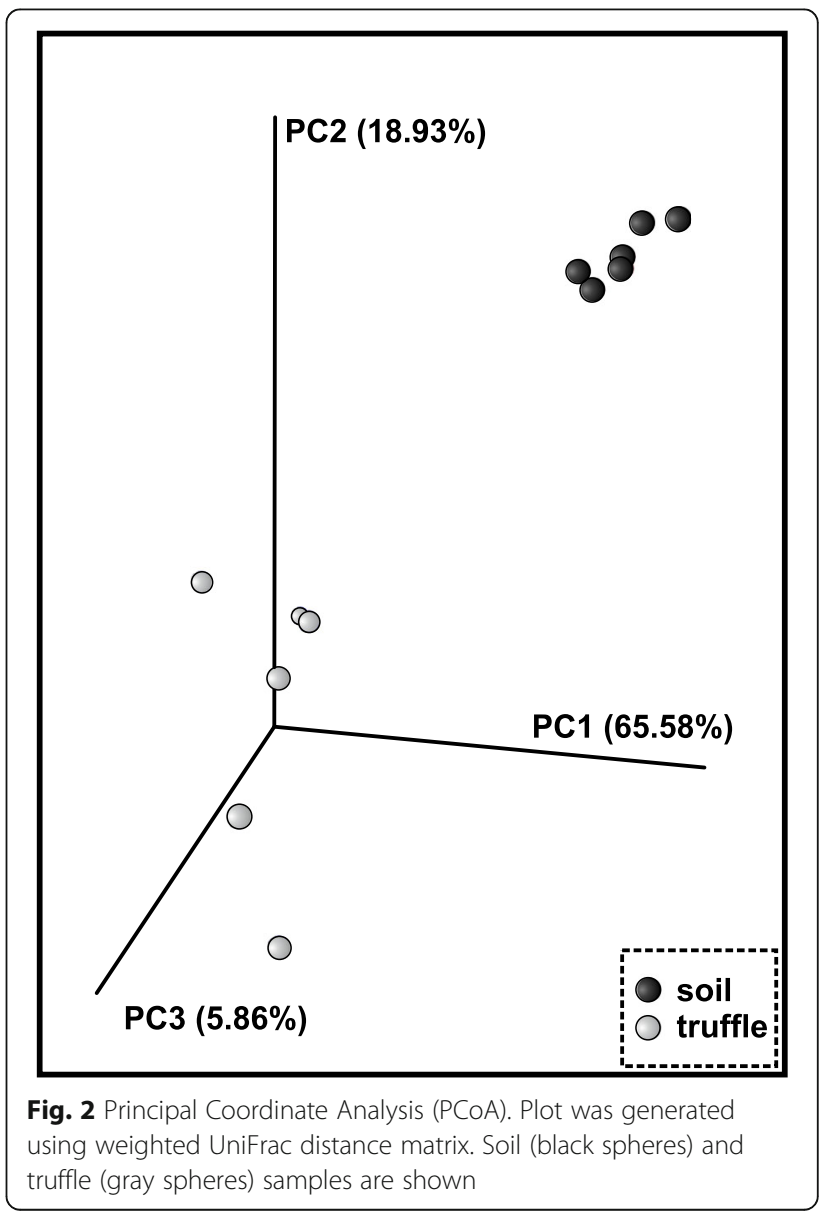




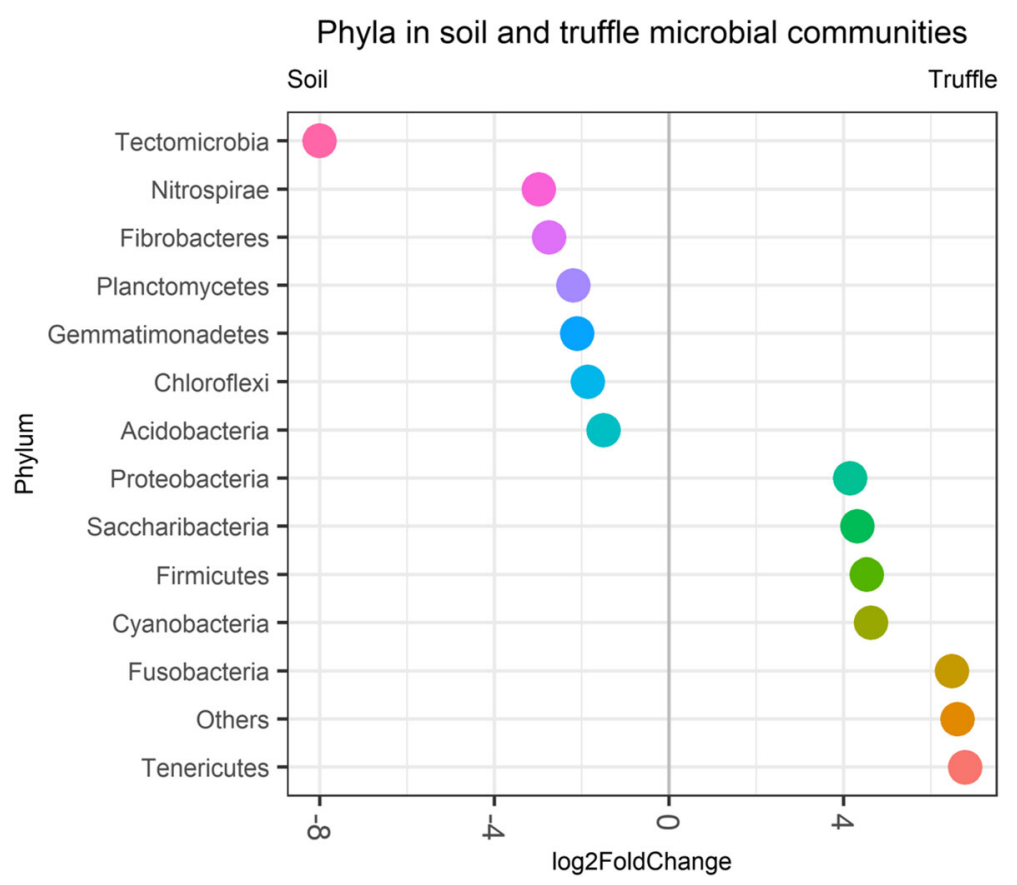

Fig. 3 Differentially abundant phyla in soil (on the left) and truffle (on the right) microbial communities

members of the Bacteria domain were found at significantly higher relative abundances in truffle (Fig. 3).

When analyzing the bacterial community composition on the whole, the main phyla retrieved in the analyzed Tuber aestivum fruiting bodies were Proteobacteria, Actinobacteria, Bacteroidetes, and Firmicutes (Fig. 4). Proteobacteria ranked first in all truffle samples, with a relative abundance between 57.6 and $95.9 \%$. The phylum Actinobacteria showed percentages ranging from 2.2 to $25.1 \%$, with Nocardioides being one of the main bacterial genera present in the ascocarps. Bacteroidetes were found in one of the truffle samples with a relative abundance of $25.9 \%$, while in the other fruiting bodies they ranged between 0.8 and $4.7 \%$. Firmicutes occurred in percentages ranging from 0.2 to $12.1 \%$.

Among Proteobacteria, the main families were represented by Bradyrhizobiaceae, Rhizobiaceae, Comamonadaceae, and Hyphomicrobiaceae, with the genera Bradyrhizobium, Rhizobium, and Devosia present in all the analyzed summer black truffles at relatively high percentages (up to $40.9 \%, 6.5 \%$, and $14.5 \%$, respectively). The family Comamonadaceae showed variable values ranging from 1.9 to $73.8 \%$, with the genera Acidovorax and Polaromonas poorly represented in most of fruiting bodies but with a relative abundance of $67.6 \%$ and $4.0 \%$ in sample 3t, respectively (Fig. 4).

In soil samples, the main phyla were Proteobacteria, Actinobacteria, Acidobacteria, Chloroflexi, and Bacteroidetes (Fig. 4). Proteobacteria occurred at percentages ranging from 34.8 to $38.7 \%$, with the genera Skermanella
(2.1-6.0\%), Bradyrhizobium (1.5-2.4\%), and Sphingomonas (1.0-4.8\%) being common to all the samples. Actinobacteria showed a relative abundance between 24.5 and $36.7 \%$, with the genera Rubrobacter and Microlunatus found at percentages ranging from 1.3 to $2.7 \%$ and from 1.7 to $2.5 \%$, respectively. An unclassified bacterium of the Acidobacteria phylum (9.2-16.2\%) ranked first in the soil sample group with a relative abundance between 5.7 and $11.2 \%$. Chloroflexi, poorly represented in truffle samples, showed percentages from 5.1 to $7.9 \%$ whereas $\mathrm{Bac}$ teroidetes ranged from 2.4 to $5.0 \%$ (Fig. 4).

In order to have an insight on the relevance and impact of cross-habitat associations between species, three microbial networks were generated for soil and truffle communities both separately and taken together, based on correlation between species abundances (Fig. 5). The topology was investigated in order to identify the most significative features of each network and keystone species relevant for their structures and organizations.

The network obtained for the soil habitat (Fig. 5a) was characterized by 747 nodes, each representing a species, and 8326 connections among them. The nodes were organized in a large connected component (clique) made of $99.19 \%$ (741) of the nodes and three dyads $(0.81 \%)$. The mean number of partners for each node of this network (mean node degree) was equal to 22.29 whereas network density was 0.0149 .

The network obtained for truffle habitat (Fig. 5b) contained 683 nodes and 28,057 connections, and it was characterized by a mean node degree of 82.16 and a 


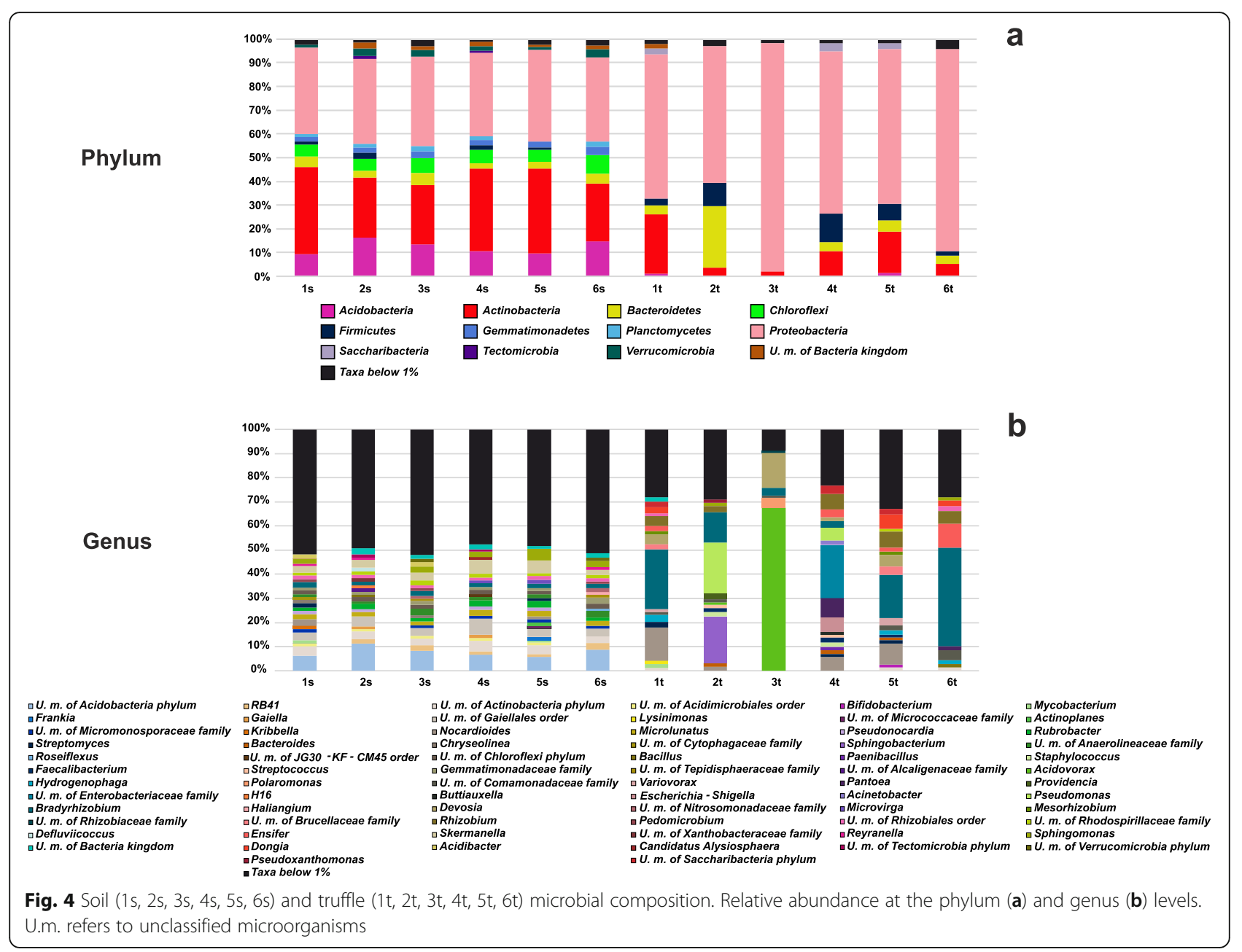

network density of 0.0601 . The largest component of the network, the clique, was made of 649 nodes which represented the $95.02 \%$ of the total nodes. A component of 28 nodes $(4.01 \%)$ was also present, and there were three dyads $(0.97 \%)$.

The network inferred by soil and truffle microbial communities combined together (Fig. 5c) was characterized by 1439 nodes organized in a large connected component (clique) comprising $99.72 \%$ of the nodes and two dyads $(0.38 \%)$. This network was also characterized by 53,721 connections, of which $8326(15.51 \%)$ were between species identified in soil habitat, 28,057 (52.27\%) were between species from truffle habitat, and 17,299 (32.22\%) were across the habitats (a partner from soil habitat, the other from the truffle habitat). The average node degree of the soil-truffle network was 74.59 , and the density was 0.026. A high number of significant cross-habitat correlations was found, suggesting that the species from the two habitats interacted or were similarly influenced by the environmental conditions.

Subsequently, the centrality of the microbial populations present in the combined habitat network was measured in order to define the relative importance of soil species with respect to the truffle ones. As shown in Fig. 5, panel d, the number of network connections between soil species was strongly and significantly lower with respect to the connections found between truffle species (Welch $t$ test $p$ value $<10^{-14}$ ) within the soiltruffle network. It is likely that those microorganisms recruited in the truffle from the soil must have a closer and stricter linkage to optimize the colonization of that specific ecological niche.

Based on betweenness centrality scores, the top five keystone OTUs in soil communities included unclassified members of the Sedimentibacter, Nitrospira, Gemmatirosa, and Dyadobacter genera, and Acidiferrobacteraceae family (Fig. 6a). For truffles, Kosakonia cowanii, Massilia sp. UMI-21, unclassified members belonging to the genera Piscinibacter and Blastococcus, and to the Polyangiaceae family represented the more relevant bacterial groups (Fig. $6 \mathrm{~b})$. On the other hand, the higher stability observed in the network showing soil and truffle microbial communities together seemed to rely on the presence and abundance of OTUs (such as Pseudomonas brassicacearum 


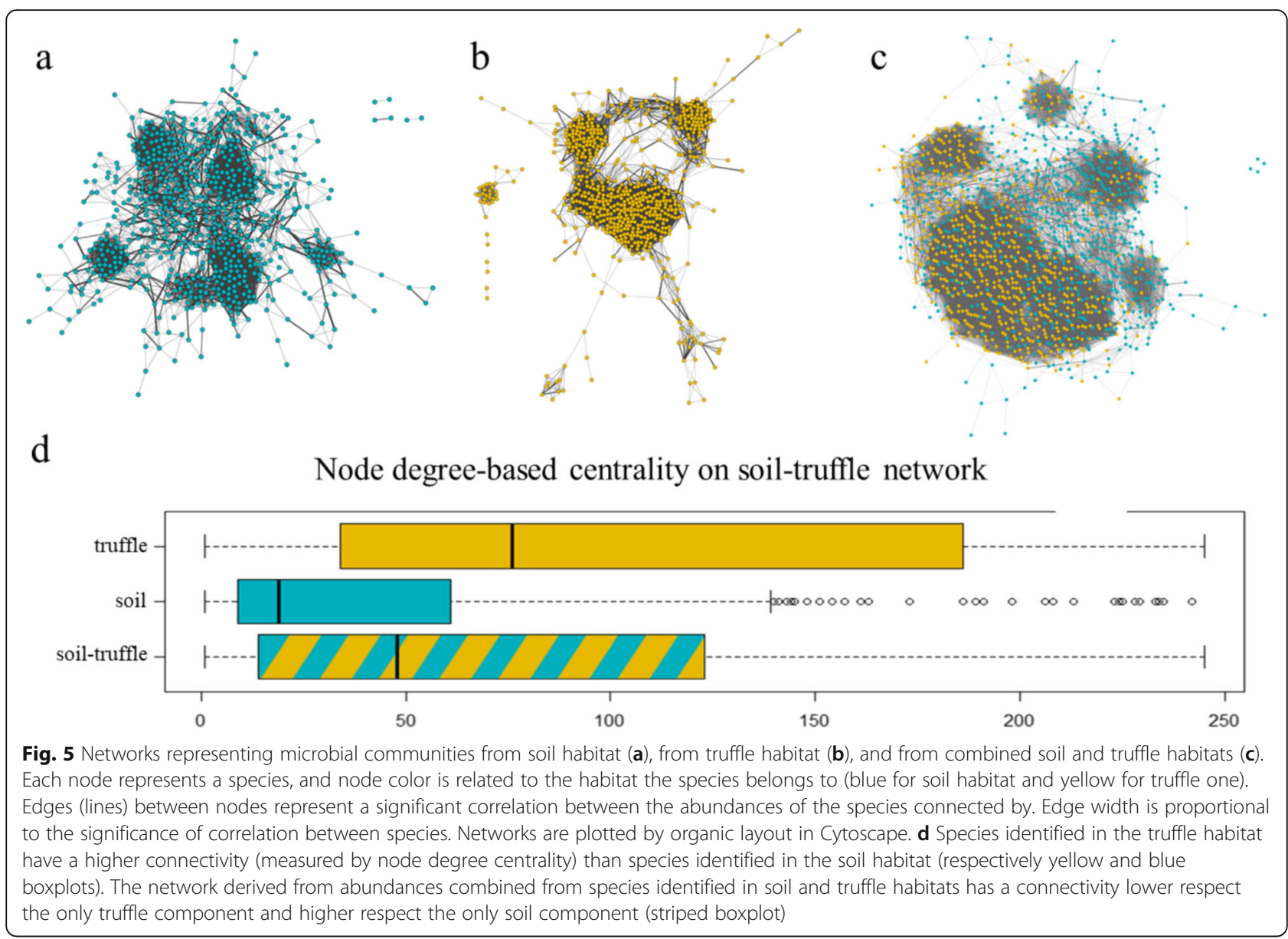

subsp. brassicacearum, Paenibacillus polymyxa, beta proteobacterium DC2b-18, and unclassified members of the Sedimentibacter genus and Saccharibacteria phylum) defining both the environments, demonstrating a more complex inter-relationship of microbial taxa (Fig. 6c) which were more closely related to one or to the other habitat. In addition, this higher stability was also shown by the analysis of the influence of species loss on the network connectivity through the measure of the "attack robustness" (Fig. 7). This analysis clearly showed that the size of the largest component of soil microbial community network decreased faster compared to truffle or soil-truffle communities whose response to robustness attack differed only of a light skew. Among all, the soil-truffle robustness attack curve showed the highest AUC values (Fig. 7). This suggested also a higher structural similarity between the truffle and soil-truffle microbial communities that is coherent with a specific recruitment of the truffle microbiota from the soil.

\section{Discussion and conclusions}

Several methods (cultivation-dependent and molecular approaches) have been employed to reveal microbial community composition and responses to environmental changes in various environments and in different contexts (Bucci et al. 2011, 2014, 2015a, 2015b; Crescenzo et al. 2017; Di Luccia et al. 2018; Petrella et al. 2018; Pietrangelo et al. 2018). In fact, an understanding of the temporal and spatial structures, functions, interactions, and population dynamics of microbial communities is critical for many aspects of life, including scientific discovery, biotechnological development, sustainable agriculture, environmental protection, and human health (Bucci et al. 2017).

In the present study, we used NGS technology to investigate microbial communities associated with summer black truffle ascocarps collected in Molise region (Southern Italy), one of the richest Italian areas of this product. Despite its economically important value, T. aestivum from Molise has received less attention from a scientific point of view compared to truffles from other Italian regions. Thus, the research aimed at filling the gap in the current knowledge by analyzing bacterial communities associated with fruiting bodies as an initial step for a further and deepened characterization. 

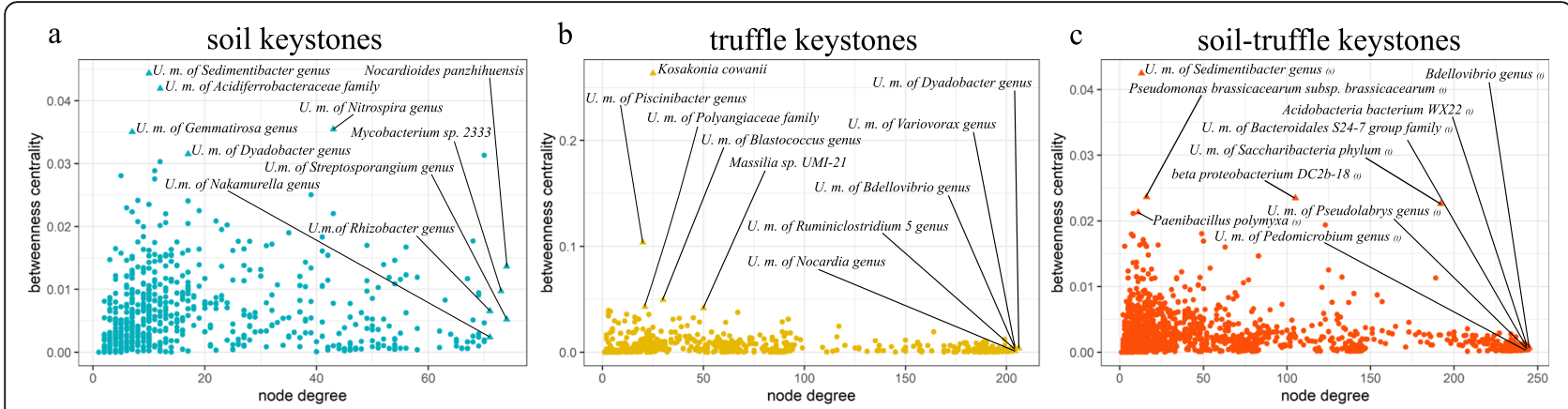

Fig. 6 Keystone species obtained from the network analysis. Nodes represent species that are shown agreeing to their centrality metrics (triangles indicate the top 5 keystone species based on node degree and betweenness centrality). Each node of a plot represents a species in the related network (a for soil, $\mathbf{b}$ for truffle, and $\mathbf{c}$ for soil-truffle). Nodes are colored according to the network they belong to (blue for soil, yellow for truffle, and red for soil-truffle). Keystone species names are showed for some of the most relevant nodes of each network. In the soil-truffle network the apex beside of species name indicates the habitat in which the species was detected: ${ }^{(s)}$ for soil and ${ }^{(t)}$ for truffle

The main bacterial phyla retrieved in the Molise truffle were the same found in the fruiting bodies of Tuber spp. of different geographic origin (Vahdatzadeh et al. 2015; Benucci and Bonito 2016; Ye et al. 2018). In fact, the analyzed communities were dominated by Proteobacteria and Actinobacteria, with the genus Bradyrhizobium particularly represented (Gryndler et al. 2013; Benucci and Bonito 2016; Ye et al. 2018).

As expected, summer black truffle microbiota was significantly different from that of soil which showed a higher $\alpha$-diversity although a high number of shared taxa at genus level. Some bacterial genera, such as Bradyrhizobium and Devosia, were detected with relatively higher abundance values in most of the fruiting bodies compared to the soil, demonstrating that most likely a recruitment of bacteria from soil to ascocarps occurs during the truffle formation, in agreement with previous researches (Antony-Babu et al. 2013; Splivallo et al. 2015).

The presence of genera comprising nitrogen-fixing bacteria (such as Bradyrhizobium and Rhizobium), as already reported for other Tuber species (Le Tacon et al. 2016), is relevant: in fact, the ability to modify nutrient availability during their biological cycle could be of particular importance during the development of fruiting bodies which need nutrients in order to complete the maturation process independently of the host plant (Barbieri et al. 2010).

The network analysis performed to elucidate the interactions between microbial taxa showed a higher robustness of the system when microbial communities were examined as a whole rather than individually. To this greater stability contributed bacterial taxa more strictly related both to one and to the other habitat, indicating
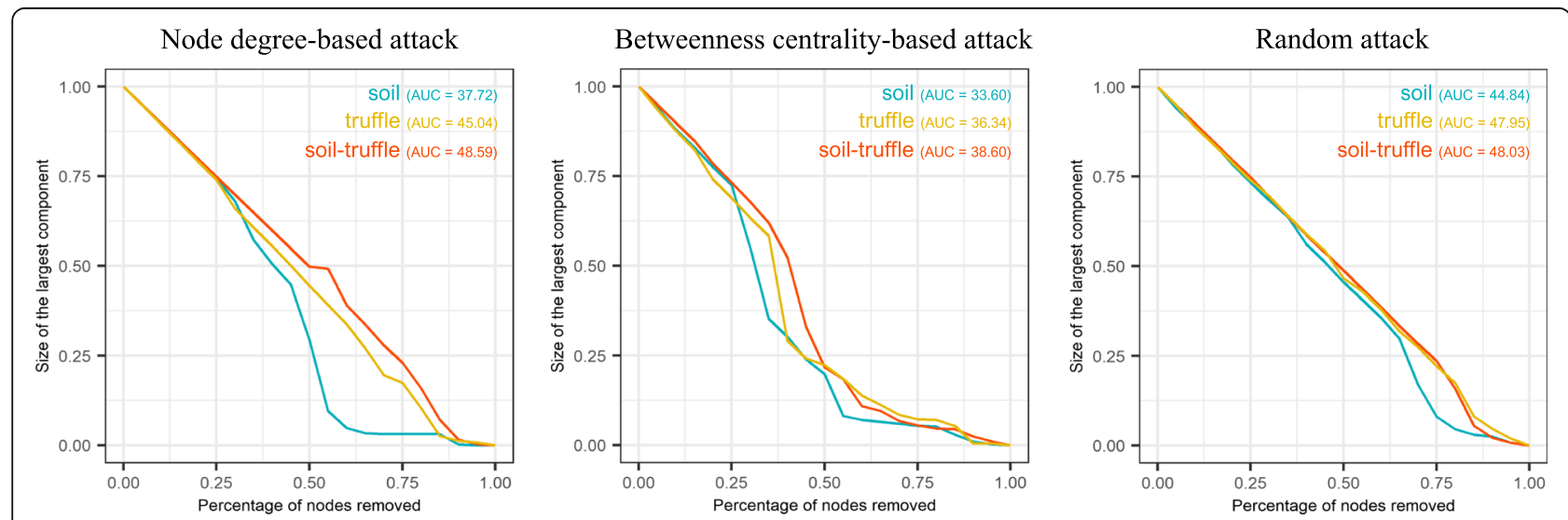

Fig. 7 Attack robustness strategy to measure network resilience. Node removal was performed in agreement with their centrality, considering both node degree (a) and betweenness centrality (b) or by a random selection (c). The robustness was measured as percentage of nodes remaining in the main connected component of the network (clique). Here we plotted the results of this analysis performed on each of the three networks as a line (blue for soil, yellow for truffle, and red for soil-truffle). On the $X$-axis are reported the percentages of nodes removed, while on the $\mathrm{Y}$-axis the percentage of the nodes remaining in the clique. AUC indicates the area under the curve calculated according to Gini's formula 
complex connections among species that could somehow determine and maintain the equilibrium of this peculiar ecosystem.

Nevertheless, a surprising and remarkable heterogeneity across truffle samples, in terms of microbial community composition and relative abundance of the main taxa, was also observed. Since the study area is small and the host plants belong to the same species, we suppose that local-specific factors could play an important role in determining the structure of the investigated truffle microbial communities. Further analyses are, thus, required to better understand which these factors are and how they could influence the composition of microbial communities. In our opinion, the full comprehension of the role of bacteria in mycorrhization process and their contribution to the development of specific traits in truffles as well as of the factors that drive the establishment of specific microbial communities in the ascocarps, could have a significant impact on truffle industry, mainly at regional scale: for the detection and identification of specific quality marks in the foodstuff (product promotion) and also for the improvement of cultivation techniques in artificial grounds.

\section{Supplementary information}

Supplementary information accompanies this paper at https://doi.org/10. 1186/s13213-020-01586-5.

Additional file 1. Venn diagram of bacterial communities with shared and unique genera between soil and truffle samples

Additional file 2. Rarefaction curves of soil (black lines) and truffle (gray lines) samples. Alpha-diversity plots obtained by using the Shannon (left) and the Chao1 (right) indices

\section{Acknowledgements}

We are grateful to Fabio D'Amico and Giuseppe Beniamino, owner of the truffle company "Tartufi - Le Ife", for their valuable contribution during truffle searching and collection.

\section{Authors' contributions}

PM: Conceptualization, Formal analysis, Investigation, Validation, Visualization, Writing-original draft, Writing-review \& editing. MT: Investigation, Writingoriginal draft. GS: Formal analysis, Writing-review \& editing. ET: Writingoriginal draft, Writing-review \& editing. GN: Conceptualization, Writingoriginal draft, Writing-review \& editing. AB: Conceptualization, Supervision Writing-original draft, Writing-review \& editing. The authors read and approved the final manuscript.

\section{Funding}

N/A.

\section{Competing interest}

The authors declare that they have no conflict of interest.

\section{Ethics approval and consent to participate}

This article does not contain any studies with human participants or animals performed by any of the authors.

\section{Consent for publication}

N/A.

\section{Author details}

'Department of Biosciences and Territory, University of Molise, Contrada Fonte Lappone, 86090 Pesche, IS, Italy. ${ }^{2}$ Department of Microbiology, ELTE Eötvös Loránd University, Pázmány P. sétány 1/C, Budapest H-1117, Hungary.

Received: 2 August 2019 Accepted: 10 January 2020

Published online: 16 June 2020

\section{References}

Antony-Babu S, Deveau A, Van Nostrand JD, Zhou J, Le Tacon F, Robin C et al (2013) Black truffle-associated bacterial communities during the development and maturation of Tuber melanosporum ascocarps and putative functional roles. Environ Microbiol 16:2831-2847 https://doi.org/10.1111/ 1462-2920.12294

Barbieri E, Bertini L, Rossi I, Ceccaroli P, Saltarelli R, Guidi C et al (2005) New evidence for bacterial diversity in the ascoma of the ectomycorrhizal fungus Tuber borchii Vittad. FEMS Microbiol Lett 247:23-35 https://doi.org/10.1016/j. femsle.2005.04.027

Barbieri E, Guidi C, Bertaux J, Frey-Klett P, Garbaye J, Ceccaroli P et al (2007) Occurrence and diversity of bacterial communities in Tuber magnatum during truffle maturation. Environ Microbiol 9:2234-2246 https://doi.org/10. 1111/j.1462-2920.2007.01338.x

Barbieri E, Ceccaroli P, Saltarelli R, Guidi C, Potenza L, Basaglia M (2010) New evidence for nitrogen fixation within the Italian white truffle Tuber magnatum. Fungal Biol 114:936-942 https://doi.org/10.1016/j.funbio.2010.09.001

Benucci GMN, Bonito GM (2016) The truffle microbiome: species and geography effects on bacteria associated with fruiting bodies of hypogeous Pezizales. Microb Ecol 72:4-8 https://doi.org/10.1007/s00248-016-0755-3

Bokulich NA, Kaehler BD, Rideout JR, Dillon M, Bolyen E, Knight R et al (2018) Optimizing taxonomic classification of marker-gene amplicon sequences with QIIME 2's q2-feature-classifier plugin. Microbiome 6:90 https://doi.org/ 10.1186/s40168-018-0470-z

Bucci A, Naclerio G, Allocca V, Celico P, Celico F (2011) Potential use of microbial community investigations to analyse hydrothermal systems behaviour: the case of Ischia Island, Southern Italy. Hydrol Process 25:1866-1873 https://doi. org/10.1002/hyp.7942

Bucci A, Petrella E, Naclerio G, Gambatese S, Celico F (2014) Bacterial migration through low-permeability fault zones in compartmentalised aquifer systems: a case study in Southern Italy. Int J Speleol 43:273-281 https://doi.org/10. 5038/1827-806X.43.3.4

Bucci A, Allocca V, Naclerio G, Capobianco G, Divino F, Fiorillo F et al (2015a) Winter survival of microbial contaminants in soil: an in situ verification. J Environ Sci 27:131-138 https://doi.org/10.1016/j.jes.2014.07.021

Bucci A, Petrella E, Naclerio G, Allocca V, Celico F (2015b) Microorganisms as contaminants and natural tracers: a 10-year research in some carbonate aquifers (southern Italy). Environ Earth Sci 74:173-184 https://doi.org/10.1007/ s12665-015-4043-1

Bucci A, Petrella E, Celico F, Naclerio G (2017) Use of molecular approaches in hydrogeological studies: the case of carbonate aquifers in southern Italy. Hydrogeol J 25:1017-1031 https://doi.org/10.1007/s10040-017-1562-8

Büntgen U, Bagi I, Fekete O, Molinier V, Peter M, Splivallo R et al (2017) New insights into the complex relationship between weight and maturity of Burgundy truffles (Tuber aestivum). Plos One 12:e0170375 https://doi.org/10. 1371/journal.pone.0170375

Busiello DM, Suweis S, Hidalgo J, Martian A (2017) Explorability and the origin of network sparsity in living systems. Sci Rep 7:12323 https://doi.org/10.1038/ s41598-017-12521-1

Callahan BJ, McMurdie PJ, Rosen MJ, Han AW, Johnson AJ, Holmes SP (2016) DADA2: high-resolution sample inference from Illumina amplicon data. Nat Methods 13:581-583 https://doi.org/10.1038/nmeth.3869

Caporaso JG, Kuczynski J, Stombaugh J, Bittinger K, Bushman FD, Costello EK et al (2010) QIIME allows analysis of high-throughput community sequencing data. Nat Methods 7:335-336 https://doi.org/10.1038/nmeth.f.303

Crescenzo R, Mazzoli A, Cancelliere R, Bucci A, Naclerio G, Baccigalupi L et al (2017) Beneficial effects of carotenoid-producing cells of Bacillus indicus HU16 in a rat model of diet-induced metabolic syndrome. Benef Microbes 8: 823-831 https://doi.org/10.3920/BM2017.0025

Di Luccia B, Mazzoli A, Cancelliere R, Crescenzo R, Ferrandino I, Monaco A et al (2018) Lactobacillus gasseri SF1183 protects the intestinal epithelium and prevents colitis symptoms in vivo. J Funct Foods 42:195-202 https://doi.org/ 10.1016/j.jff.2017.12.049 
Freeman LC (1977) A set of measures of centrality based on betweenness. Sociometry 40:35-41 https://doi.org/10.2307/3033543

Grilli J, Adorisio M, Suweis S, Barabás G, Banavar JR, Allesina S et al (2017) Feasibility and coexistence of large ecological communities. Nat Commun 8: 14389 https://doi.org/10.1038/ncomms14389

Gryndler M, Soukupová L, Hršelová H, Gryndlerová H, Borovička J, Streiblová E et al (2013) A quest for indigenous truffle helper prokaryotes. Env Microbiol Rep 5:346-352 https://doi.org/10.1111/1758-2229.12014

Harrell FE Jr, Dupont C et al (2019) Hmisc: Harrell Miscellaneous. R package version 4.2-0. https://CRAN.R-project.org/package $=$ Hmisc

lotti M, Piattoni F, Leonardi P, Hall IR, Zambonelli A (2016) First evidence for truffle production from plants inoculated with mycelial pure cultures. Mycorrhiza 26:793-798 https://doi.org/10.1007/s00572-016-0703-6

lyer S, Killingback T, Sundaram B, Wang Z (2013) Attack robustness and centrality of complex networks. PLoS One 8:e59613 https://doi.org/10.1371/journal. pone.0059613

Le Tacon F, Rubini A, Murat C, Riccioni C, Robin C, Belfiori B et al (2016) Certainties and uncertainties about the life cycle of the Périgord black truffle (Tuber melanosporum Vittad.). Ann For Sci 73:105-117 https://doi.org/10. 1007/s13595-015-0461-1

Leclerc RD (2008) Survival of the sparsest: robust gene networks are parsimonious. Mol Syst Biol 4:213 https://doi.org/10.1038/msb.2008.52

Liu YY, Slotine JJ, Barabási AL (2011) Controllability of complex networks. Nature 473:167-173 https://doi.org/10.1038/nature10011

Love Ml, Huber W, Anders S (2014) Moderated estimation of fold change and dispersion for RNA-seq data with DESeq2. Genome Biol 15:550 https://doi. org/10.1186/s13059-014-0550-8

Lozupone C, Knight R (2005) UniFrac: A new phylogenetic method for comparing microbial communities. Appl Environ Microb 71:8228-8235 https://doi.org/10.1128/AEM.71.12.8228-8235.2005

Mäkelä MR, Marinović M, Nousiainen P, Liwanag AJ, Benoit I, Sipilä J et al (2015) Aromatic metabolism of filamentous fungi in relation to the presence of aromatic compounds in plant biomass. Adv Appl Microbiol 91:63-137 https://doi.org/10.1016/bs.aambs.2014.12.001

Mello A, Balestrini R (2018) Recent insights on biological and ecological aspects of ectomycorrhizal fungi and their interactions. Front Microbiol 9:216 https:// doi.org/10.3389/fmicb.2018.00216

Milani C, Hevia A, Foroni E, Duranti S, Turroni F, Lugli GA et al (2013) Assessing the fecal microbiota: an optimized ion torrent $16 \mathrm{~S}$ rRNA gene-based analysis protocol. PLoS One 8:e68739 https://doi.org/10.1371/journal.pone.0068739

Nacher JC, Akutsu T (2013) Structural controllability of unidirectional bipartite networks. Sci Rep 3:1647 https://doi.org/10.1038/srep01647

Oliveros JC (2007-2015) Venny. An interactive tool for comparing lists with Venn's diagrams. http://bioinfogp.cnb.csic.es/tools/venny/index.html

Pacioni G, Cerretani L, Procida G, Cichelli A (2014) Composition of commercia truffle flavored oils with GC-MS analysis and discrimination with an electronic nose. Food Chem 146:30-35 https://doi.org/10.1016/j.foodchem.2013.09.016

Pavić A, Stanković S, Saljnikov E, Krüger D, Buscot F, Tarkka M et al (2013) Actinobacteria may influence white truffle (Tuber magnatum Pico) nutrition, ascocarp degradation and interactions with other soil fungi. Fungal Ecol 6: 527-538 https://doi.org/10.1016/j.funeco.2013.05.006

Pavlopoulos GA, Secrier M, Moschopoulos CN, Soldatos TG, Kossida S, Aerts J et al (2011) Using graph theory to analyze biological networks. BioData Min 4:10 https://doi.org/10.1186/1756-0381-4-10

Petrella E, Bucci A, Ogata K, Zanini A, Naclerio G, Chelli A et al. (2018) Hydrodynamics in evaporate-bearing fine-grained successions investigated through an interdisciplinary approach: a test study in Southern Italyhydrogeological behaviour of heterogeneous low-permeability media. Geofluids Volume 2018, Article ID 5978597, 15 pp. https://doi.org/10.1155/ 2018/5978597

Pietrangelo L, Bucci A, Maiuro L, Bulgarelli D, Naclerio G (2018) Unraveling the composition of the root-associated bacterial microbiota of Phragmites australis and Typha latifolia. Front Microbiol 9:1650 https://doi.org/10.3389/ fmicb.2018.01650

Quast C, Pruesse E, Yilmaz P, Gerken J, Schweer T, Yarza P (2013) The SILVA ribosomal RNA gene database project: improved data processing and webbased tools. Nucleic Acids Res 41:D590-D596 https://doi.org/10.1093/nar/ gks1219

R Core Team (2019) R: A language and environment for statistical computing. R foundation for statistical Computing, Vienna, Austria URL https://www.Rproject.org/
Ruiz VE, Battaglia T, Kurtz ZD, Bijnens L, Ou A, Engstrand I et al (2017) A single early-in-life macrolide course has lasting effects on murine microbial network topology and immunity. Nat Commun 8:518 https://doi.org/10.1038/s41467017-00531-6

Sbrana C, Agnolucci M, Bedini S, Lepera A, Toffanin A, Giovannetti M et al (2002) Diversity of culturable bacterial populations associated to Tuber borchii ectomycorrhizas and their activity on T. borchii mycelial growth. FEMS Microbiol Lett 211:195-201 https://doi.org/10.1111/j.1574-6968.2002.tb11224.x

Schmidberger PC, Schieberle P (2017) Characterization of the key aroma compounds in white Alba truffle (Tuber magnatum pico) and Burgundy truffle (Tuber uncinatum) by means of the sensomics approach. J Agric Food Chem 65:9287-9296 https://doi.org/10.1021/acs.jafc.7b04073

Shannon P, Markiel A, Ozier O, Baliga NS, Wang JT, Ramage D et al (2003) Cytoscape: a software environment for integrated models of biomolecular interaction networks. Genome Res 13:2498-2504 http://www.genome.org/ cgi/doi/10.1101/gr.1239303

Splivallo R, Deveau A, Valdez N, Kirchhoff N, Frey-Klett P, Karlovsky P (2015) Bacteria associated with truffle fruiting bodies contribute to truffle aroma. Environ Microbiol 17:2647-2660 https://doi.org/10.1111/1462-2920.12521

Suweis S, Simini F, Banavar JR, Maritan A (2013) Emergence of structural and dynamical properties of ecological mutualistic networks. Nature 500:449-452 https://doi.org/10.1038/nature12438

Vahdatzadeh M, Deveau A, Splivallo R (2015) The role of the microbiome of truffles in aroma formation: a meta-analysis approach. Appl Environ Microb 81:6946-6952 https://doi.org/10.1128/AEM.01098-15

Vita F, Taiti C, Pompeiano A, Bazihizina N, Lucarotti V, Mancuso S et al (2015) Volatile organic compounds in truffle (Tuber magnatum Pico): comparison of samples from different regions of Italy and from different seasons. Sci Rep 5: 12629 https://doi.org/10.1038/srep12629

Welch BL (1947) The generalisation of student's problems when several different population variances are involved. Biometrika 34:28-35 https://doi.org/10. 1093/biomet/34.1-2.28

Ye L, Li Q, Fu Y, Sourzat P, Tan H, Zou J et al (2018) Host species effects on bacterial communities associated with the fruiting bodies of Tuber species from the Sichuan Province in Southwest China. Mycol Prog 17:833-840 https://doi.org/10.1007/s11557-018-1397-2

\section{Publisher's Note}

Springer Nature remains neutral with regard to jurisdictional claims in published maps and institutional affiliations.
Ready to submit your research? Choose BMC and benefit from:

- fast, convenient online submission

- thorough peer review by experienced researchers in your field

- rapid publication on acceptance

- support for research data, including large and complex data types

- gold Open Access which fosters wider collaboration and increased citations

- maximum visibility for your research: over $100 \mathrm{M}$ website views per year

At $\mathrm{BMC}$, research is always in progress.

Learn more biomedcentral.com/submissions 